\title{
Validation of GPS atmospheric water vapor with WVR data in satellite tracking mode
}

\author{
M. Shangguan ${ }^{1, *}$, S. Heise ${ }^{1}$, M. Bender ${ }^{2}$, G. Dick ${ }^{1}$, M. Ramatschi ${ }^{1}$, and J. Wickert ${ }^{1}$ \\ ${ }^{1}$ Department 1.1 GPS/Galileo Earth Observations, Helmholtz Centre Potsdam, German Research Centre for Geosciences \\ (GFZ), Potsdam, Germany \\ ${ }^{2}$ Deutscher Wetterdienst (DWD), Data Assimilation Unit, Frankfurter Str. 135, 63067 Offenbach, Germany \\ *present address: GEOMAR Helmholz Centre for Ocean Research Kiel, Kiel, Germany
}

Correspondence to: M. Shangguan (sgming@gfz-potsdam.de)

Received: 2 July 2014 - Revised: 7 December 2014 - Accepted: 9 December 2014 - Published: 13 January 2015

\begin{abstract}
Slant-integrated water vapor (SIWV) data derived from GPS STDs (slant total delays), which provide the spatial information on tropospheric water vapor, have a high potential for assimilation to weather models or for nowcasting or reconstruction of the 3-D humidity field with tomographic techniques. Therefore, the accuracy of GPS STD is important, and independent observations are needed to estimate the quality of GPS STD. In 2012 the GFZ (German Research Centre for Geosciences) started to operate a microwave radiometer in the vicinity of the Potsdam GPS station. The water vapor content along the line of sight between a ground station and a GPS satellite can be derived from GPS data and directly measured by a water vapor radiometer (WVR) at the same time. In this study we present the validation results of SIWV observed by a ground-based GPS receiver and a WVR. The validation covers 184 days of data with dry and wet humidity conditions. SIWV data from GPS and WVR generally show good agreement with a mean bias of $-0.4 \mathrm{~kg} \mathrm{~m}^{-2}$ and an rms (root mean square) of $3.15 \mathrm{~kg} \mathrm{~m}^{-2}$. The differences in SIWV show an elevation dependent on an rms of $7.13 \mathrm{~kg} \mathrm{~m}^{-2}$ below $15^{\circ}$ but of $1.76 \mathrm{~kg} \mathrm{~m}^{-2}$ above $15^{\circ}$. Nevertheless, this elevation dependence is not observed regarding relative deviations. The relation between the differences and possible influencing factors (elevation angles, pressure, temperature and relative humidity) are analyzed in this study. Besides the elevation, dependencies between the atmospheric humidity conditions, temperature and the differences in SIWV are found.
\end{abstract}

Keywords. History of geophysics (geodesy) - meteorology and atmospheric dynamics (instruments and techniques) - radio science (remote sensing)

\section{Introduction}

Atmospheric water vapor is the most important greenhouse gas, which transports energy and affects physical processes in the troposphere. Thus, precise knowledge of the water vapor distribution in the atmosphere is important for weather prediction and climate research. However, the temporal and spatial water vapor distribution has a strong variability. The GFZ (German Research Centre for Geosciences) uses observations from a ground-based GPS network to investigate variations in the atmospheric water vapor over Germany, which are available with a high temporal and spatial resolution under all weather conditions. Global Positioning System (GPS) water vapor products (zenith total delay (ZTD) and STD) in near real time are provided at the GFZ. GPS data at the GFZ are processed using the Earth Parameter and Orbit determination System (EPOS) software (Gendt et al., 1998), which is based on the least squares adjustment of undifferenced observations. The derived ZTDs have an accuracy of 6-13 $\mathrm{mm}$ and are estimated every $15 \mathrm{~min}$ (Gendt et al., 2004).

Many studies (e.g., Bevis et al., 1992; Emardson et al., 1998; Gendt et al., 2004) have shown that integrated water vapor (IWV) can be determined with an accuracy better than $2 \mathrm{~kg} \mathrm{~m}^{-2}$ using GPS observations. Many countries in different continents (e.g., the United States, countries in Europe, 
Japan) have developed their own regional or national groundbased GPS networks to provide IWV (Wolfe and Gutman, 2000; Gendt et al., 2004; Shoji, 2009). Monitoring IWV temporal and spatial variability on a local scale plays an important role in operational weather forecasts, since the GPS IWV data have been included in weather forecast models (Gutman et al., 2004; Smith et al., 2007; Bennitt and Jupp, 2012). However, IWV estimations do not provide any information on the vertical distribution of water vapor, which can be derived from slant-integrated water vapor (SIWV) (Ware et al., 1997). On the other hand, the accuracy of GPS SIWVs is difficult to estimate due to the complex processing. Important applications of the slant measurements are the assimilation of weather models, nowcasting and reconstruction of 3-D humidity fields by means of tomographic techniques (Bender et al., 2011; Shangguan, 2014).

To study the accuracy of GPS SIWV many studies were carried out in different regions and at different times (e.g., Braun et al., 2003; Bender et al., 2008; Deng et al., 2011). These investigations are mainly restricted to a few days or months. Recently Shangguan (2014) used 3 months (October-December) of water vapor radiometer (WVR) data in the Black Forest for validation with GPS STDs, but the water vapor amounts were relatively low in this time period. Furthermore, in all these studies temporal and spatial interpolation had to be used because there were too few WVR observations at the same time and in the same direction as the GPS observations. The water vapor distribution varies with the latitude, the season and the topographical features. Further studies with longer data sets, especially during various weather conditions, are required to analyze all possible influential factors for the accuracy of GPS SIWV.

For this purpose the GFZ will be starting to operate a WVR in the vicinity of the Potsdam GPS station to make a longterm study under different atmospheric conditions. In this study we use WVR data from the GFZ's microwave radiometer, which can be operated in a dedicated satellite tracking mode providing SIWV observations along the line of sight for all visible GPS satellites. The main focus is to test dependences between the possible influential factors and SIWV observations on seasonal and semiannual timescales.

In Sect. 2 we describe the WVR and GPS data used as well as the method to derive SIWV from GPS STDs. The results of their comparison and the relationship of these results to possible influential factors are discussed in Sect. 3. In the final section the conclusions and future work are outlined.

\section{Data sources}

The 6-channel microwave radiometer HATPRO (Humidity and Temperature Profiler) from Radiometer Physics (www. radiometer-physics.de) is deployed in the vicinity of the GPS station Potsdam $\left(52.38^{\circ} \mathrm{N}, 13.07^{\circ} \mathrm{E} ; 103.679 \mathrm{~m}\right.$ above sea level) ( $\sim 10 \mathrm{~m}$ distance). The accuracy of IWV measured by the HATPRO is about $0.7 \mathrm{~kg} \mathrm{~m}^{-2}$ (Rose et al., 2005; Kneifel et al., 2009). For this study WVR observations are compared with GPS SIWV observations covering the time period from 1 January to 4 July 2013 . Within this period rather dry $\left(\sim 1 \mathrm{~kg} \mathrm{~m}^{-2}\right)$ and wet $\left(\sim 45 \mathrm{~kg} \mathrm{~m}^{-2}\right)$ weather conditions can be studied. Both the GPS and WVR data used in this study are described in the following sections.

\subsection{GPS data processing}

GPS STDs, i.e. the signal delays along each single signal path, have been derived from the EPOS software (Gendt et al., 1998) using a time resolution of $2.5 \mathrm{~min}$ and an elevation cutoff angle of $7^{\circ}$. In EPOS the precise point positioning (PPP) (Zumberge et al., 1997) based on the undifferenced phase and code observations with proper weights scaled according to elevation angles is implemented. In PPP mode, the precise orbits and clocks of all GPS satellites required by the PPP analysis are determined by further refining the IGS (International GNSS Service) routine products (Gendt et al., 2011). Each station is processed independently by PPP and the processing of a large number of stations can be easily parallelized in near real time. ZTDs are processed using a $12 \mathrm{~h}$ sliding window shifted each hour, and STDs are reconstructed every $150 \mathrm{~s}$. Tropospheric delays are estimated using the Saastamoinen model of the ZHD (zenith hydrostatic delay) and the global mapping function (GMF) (Boehm et al., 2006b). The remaining tropospheric impact is parameterized in zenith delays with 15 min resolution, and the gradients are estimated every hour. Then STDs are retrieved as a combination of different estimates (Bender et al., 2011; Shangguan et al., 2013):

$\mathrm{STD}=m_{\mathrm{h}} \cdot \mathrm{ZHD}+m_{\mathrm{w}} \cdot(\mathrm{ZWD}+D)+\delta$
$D=\cot \epsilon\left(G_{\mathrm{N}} \cos \alpha+G_{\mathrm{E}} \sin \alpha\right)$,

where ZHD and ZWD are the hydrostatic and the wet zenith delay, $m_{\mathrm{h}}$ and $m_{\mathrm{W}}$ are the hydrostatic and the wet mapping function, $G_{\mathrm{N}}$ and $G_{\mathrm{E}}$ are the delay gradient parameters in the northern and eastern direction, $\epsilon$ is the elevation angle, $\alpha$ is the azimuth angle and $\delta$ is the postfit phase residual.

As described above, STDs can be obtained by GPS data processing techniques, but WVR provides IWV along a given line of sight. Therefore, GPS STDs are converted into SIWV for the validation. The STD delay can be divided into a hydrostatic and a wet component. The hydrostatic part can be calculated with the Saastamoinen ZHD model using the surface pressure $\left(P_{0}\right)$ at the station (Davis et al., 1985; Bevis et al., 1992):

$\mathrm{ZHD}=\frac{0.0022768 P_{0}}{1-0.0026 \cos (2 \phi)-0.00028 h}$,

where $h$ is the height above geoid in $\mathrm{km}, P_{0}$ is the surface pressure in $\mathrm{hPa}$ and $\phi$ is the geodetic latitude of the observing site. ZHD can be mapped onto the individual slant path by 
using the hydrostatic global mapping function $m_{\mathrm{h}}$ :

$\mathrm{SHD}=m_{\mathrm{h}} \cdot \mathrm{ZHD}$.

Secondly, the slant wet delay (SWD) or the zenith wet delay can be separated from the STD/ZTD by the estimated hydrostatic delay (SHD/ZHD):

$\mathrm{ZWD}=\mathrm{ZTD}-\mathrm{ZHD}$

$\mathrm{SWD}=\mathrm{STD}-\mathrm{SHD}$.

Then the ZWD/SWD is converted into the IWV/SIWV using a relationship based on the surface temperature (Bevis et al., 1994):

$\mathrm{IWV}=\Pi \cdot \mathrm{ZWD}$

$\mathrm{SIWV}=\Pi \cdot \mathrm{SWD}$,

where $\Pi$ is a temperature dependent factor:

$\Pi=\frac{10^{6}}{\rho R_{\mathrm{V}}\left(\frac{C_{1}}{T_{m}}+C_{2}\right)}$,

where $C_{1}=373900 \mathrm{~K}^{2} \mathrm{hPa}^{-1}$ and $C_{2}=22.1 \mathrm{KhPa}^{-1}$ are the refractivity coefficient, $\rho$ is the mass density of liquid water, $R_{\mathrm{v}}$ is the gas constant for water vapor, and $T_{m}$ is a weighted temperature of the atmosphere:

$T_{m}=\frac{\int \frac{e}{T} \mathrm{~d} h}{\int \frac{e}{T^{2}} \mathrm{~d} h} \approx 70.2+0.72 T_{0}$,

where $T_{0}$ is the surface temperature in $\mathrm{K}$ and $e$ is the water vapor pressure. This approximation is accurate to $2 \%$ for all weather conditions (Bevis et al., 1994).

\subsection{WVR data}

The GFZ HATPRO WVR exploits the microwave spectrum emitted by atmospheric water molecules at different wavelengths to derive information on atmospheric liquid water and IWV. It can clearly identify the spatial and temporal distribution of clouds and IWV by measuring the absorption lines of atmospheric water vapor at frequencies between 22.24 and $27.84 \mathrm{GHz}$ and a window channel at $31.4 \mathrm{GHz}$ for the liquid water. The HATPRO can measure the SIWV directly in satellite direction by applying the GPS tracking mode. For the tracking, GPS ephemeris data derived via HATPRO's built-in GPS receiver are used to determine the satellite positions. Then, the radiometer can periodically scan a number of visible GPS satellites. This allows a comparison of the measured WVR SIWVs with the GPS SIWVs without interpolation.

The rain-flagged data are excluded. In addition, only WVR data observations with atmospheric liquid water (ALW) below $1 \mathrm{~kg} \mathrm{~m}^{-2}$ were used for the comparison. If the ALW is too large, ALW can distort the measurement of the brightness
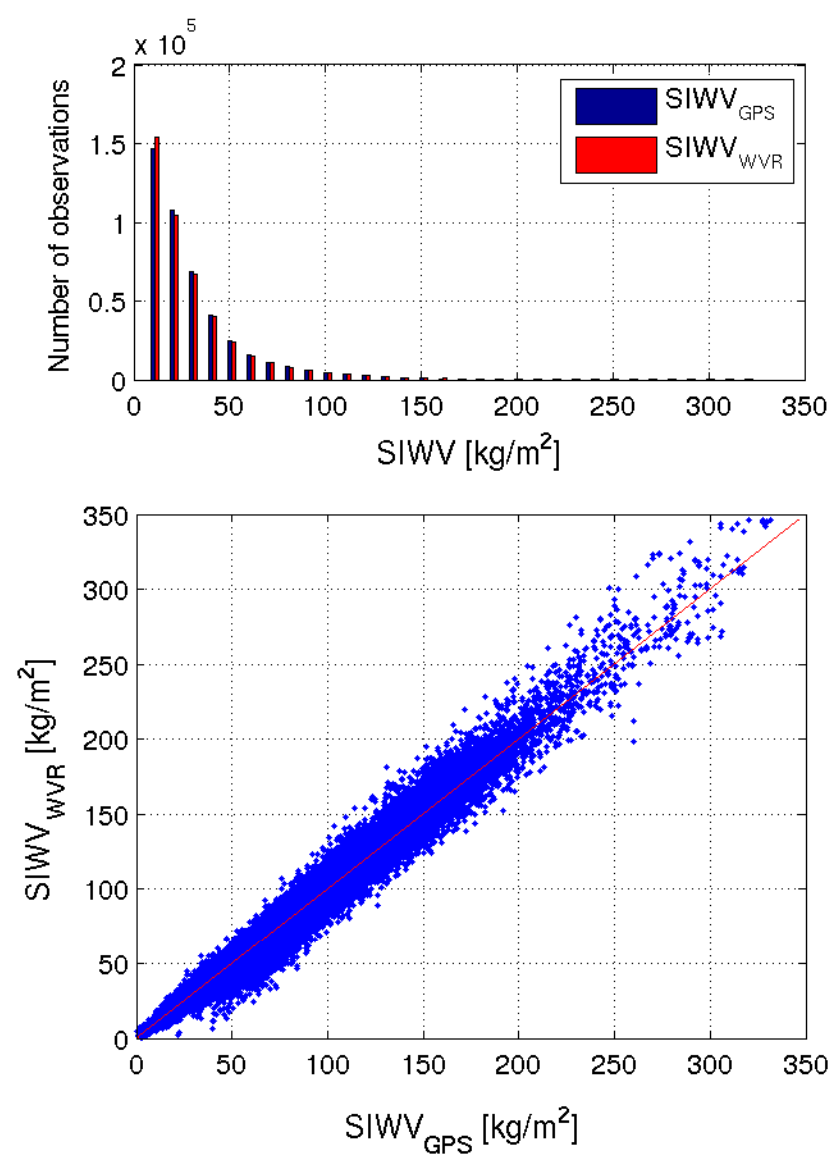

Figure 1. Histogram of the SIWV observations (top) from 1 January to 4 July 2013; scatterplot of SIWV observations from GPS and WVR (bottom)

temperature. As a consequence, the measured WVR SIWVs can be extremely high.

There were differences between elevation and azimuth angles of the GPS and WVR data due to small time differences $(\sim 1.25 \mathrm{~min})$. The derived GPS SIWVs were matched to the nearest WVR measurements where a maximum deviation in the intersection angle of $2^{\circ}$ was accepted. The zenith-mapped SIWVs were calculated with the following formula:

$\mathrm{IWV}_{z}=\operatorname{SIWV} / m_{\mathrm{w}}$.

\section{Results and discussion}

For the validation the differences in SIWV and zenithmapped SIWV $\left(\operatorname{IWV}_{z}\right)$ were calculated:

$\Delta_{\mathrm{SIWV}}=\mathrm{SIWV}_{\mathrm{GPS}}-\mathrm{SIWV}_{\mathrm{WVR}}$
$\Delta_{\mathrm{IWV}_{z}}=\mathrm{IWV}_{z, \mathrm{GPS}}-\mathrm{IWV}_{z, \mathrm{WVR}}$.

Table 1 shows the statistical result of the validation. The mean difference in SIWV is $0.4 \mathrm{~kg} \mathrm{~m}^{-2}$, with a standard de- 
Table 1. Statistical data of the comparison between GPS and WVR data. $\Delta_{\mathrm{SIWV}}$ : differences in slant-integrated water vapor (SIWV) GPS - WVR; $\Delta_{\mathrm{IWV}_{z}}$ : differences in zenith-mapped SIWV; SD: standard deviation; rms: root mean square; $N$ : number of compared observations.

\begin{tabular}{lccccc}
\hline Differences & $\Delta_{\text {SIWV }}$ & $\Delta_{\text {SIWV }}$ & $\Delta_{\text {SIWV }}$ & $\Delta_{\mathrm{IWV}_{z}}$ & $\Delta_{\mathrm{IWV}_{z}}$ \\
\hline Elevation & $>7^{\circ}$ & $<15^{\circ}$ & $>15^{\circ}$ & $>7^{\circ}$ & $>15^{\circ}$ \\
$N$ & 446934 & 62114 & 384820 & 446934 & 384820 \\
Mean $\left[\mathrm{kg} \mathrm{m}^{-2}\right]$ & 0.40 & 0.51 & 0.38 & 0.28 & 0.28 \\
$\mathrm{SD}\left[\mathrm{kg} \mathrm{m}^{-2}\right]$ & 3.12 & 7.13 & 1.76 & 0.96 & 0.95 \\
rms $\left[\mathrm{kg} \mathrm{m}^{-2}\right]$ & 3.15 & 7.15 & 1.80 & 1.00 & 0.99 \\
\hline
\end{tabular}
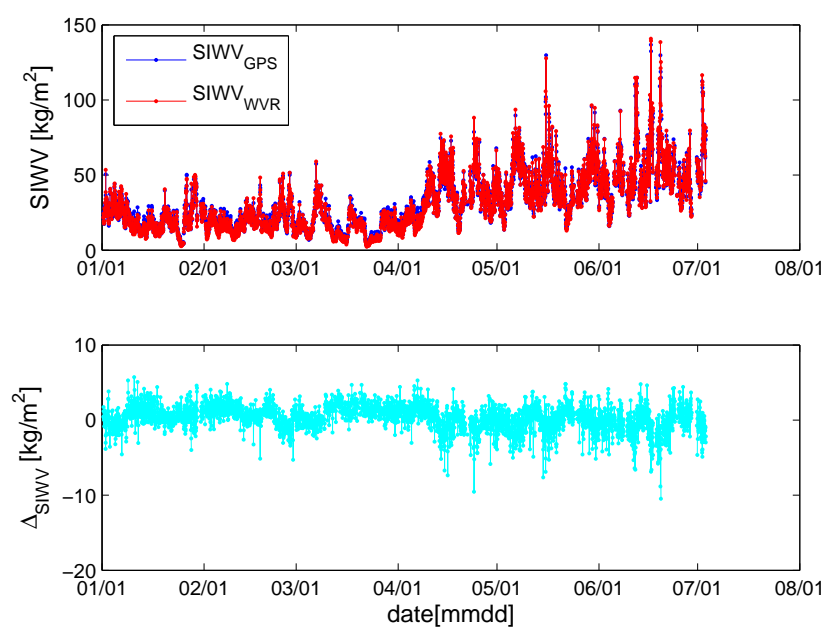

Figure 2. Hourly mean of SIWV observations derived from GPS (blue), WVR (red) and their differences (cyan) from 1 January to 4 July 2013; $\Delta_{\text {SIWV }}$ is the difference in SIWV (GPS - WVR).

viation (SD) of $3.12 \mathrm{~kg} \mathrm{~m}^{-2}$. Weather conditions during this time were variable, with IWVs ranging from 1 to $45 \mathrm{~kg} \mathrm{~m}^{-2}$. This broad range was captured in this data set of 446934 observations over 6 months. These characteristics indicate that this analysis is a much more robust comparison than the data set reported in Shangguan (2014), in which the maximal zenith-mapped water vapor amounts were smaller than $35 \mathrm{~kg} \mathrm{~m}^{-2}$. The root mean square (rms) of $\Delta_{\mathrm{SIWV}}$ is $3.15 \mathrm{~kg} \mathrm{~m}^{-2}$, with a cutoff elevation angle of $7^{\circ}$, in which most large differences are located at a low elevation. With a cutoff elevation angle of $15^{\circ}$, the rms of $\Delta_{\text {SIWV }}$ is only $1.80 \mathrm{~kg} \mathrm{~m}^{-2}$. In contrast, the rms of $\Delta_{\mathrm{IWV}_{z}}$ is almost same for different cutoff elevation angles. Regarding the assumable measurement accuracy, GPS and WVR SIWVs are comparable to each other.

Figure 1 (bottom) shows the scatterplot of all observations. It indicates the good agreement between GPS and WVR data. The distribution of observations can be seen in Fig. 1 (top). Most of the compared SIWV observations are smaller than $50 \mathrm{~kg} \mathrm{~m}^{-2}$. Figure 2 shows time series of the hourly mean SIWV from GPS and WVR and their differences. There are some gaps (up to $36 \mathrm{~h}$ ) in the WVR data due to rain events

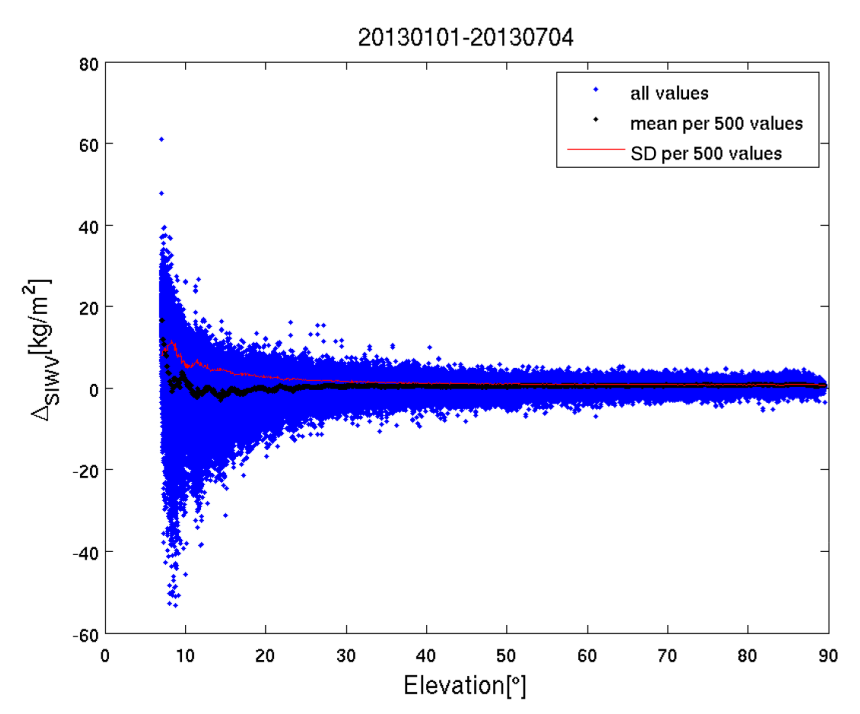

Figure 3. Relation between $\Delta_{\text {SIWV }}$ and elevation angles. Blue points are all validation values. Black points are means of every 500 observations along the $x$ axis, and the red line is their corresponding SD.

and high ALW during the 184 days. For each hour the mean values of SIWVs were calculated to get a good overview of the change in the SIWVs. The overall impression of the validation is that GPS SIWVs are consistent with WVR observations on average. However, the SIWV differences vary significantly with the time. The SIWV bias between GPS and WVR varies from positive to negative values. To study these variations, attempts are made to correlate the SIWV differences with atmospheric parameters, which usually vary with periods of hours, days or weeks. The relation between the SIWV differences and possible influential factors (elevation angles and meteorological conditions) are studied in the following sections.

\subsection{Dependency of the bias on the elevation angle}

The elevation angle plays an important role in data processing. The mapping function error is large on the low elevation angle (Boehm et al., 2006a), and the scattering and multipath effects on the GPS signal are typical problems at low elevation angles in the GPS data processing (Ning et al., 2011). 


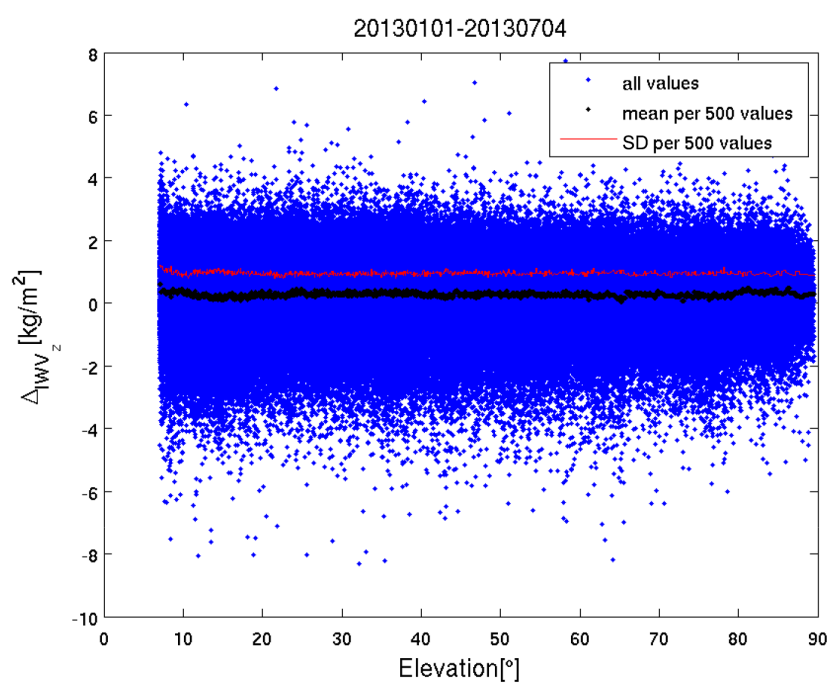

Figure 4. Relation between $\Delta_{\mathrm{IWV}_{z}}$ and elevation angles. Blue points are all validation values. Black points are means of every 500 values along the $x$ axis, and the red line is their corresponding SD.

Also, WVR data at low elevation angles can be influenced by ground radiation sources. Therefore, it is necessary to study the dependency of the GPS - WVR variations on the elevation. The SD of $\Delta_{\text {SIwV }}$ strongly increases with decreasing elevation angles (Fig. 3). The data with elevation angles below $15^{\circ}$ have obviously larger biases with a larger SD, but, above about $30^{\circ}$, the bias and SD of $\Delta_{\text {SIWV }}$ show no significant dependence on elevation. In contrast, the variations in $\Delta_{\mathrm{IWV}_{z}}$ and also relative $\Delta_{\text {SIWV }}$ (not shown here) have a low dependence on elevation for the whole elevation range (Fig. 4). $\Delta_{\mathrm{IWV}_{z}}$ are mainly in the range of $\left[-4 \mathrm{~kg} \mathrm{~m}^{-2}, 4 \mathrm{~kg} \mathrm{~m}^{-2}\right]$, while $\Delta_{\text {SIWV }}$ show a strong variability at low elevation angles.

\subsection{Dependency of validation results on atmospheric humidity conditions}

Furthermore, the relation between $\Delta_{\mathrm{SIWV}}$ and humidity conditions is studied. Typically, the amount of IWV shows strong variations with time. To classify the humidity conditions, within this study we used WVR IWVs measured within time periods close to each other. About 203202 observations have corresponding WVR IWVs within a time interval of \pm 3 min. It was checked whether the bias and SD of $\Delta_{\mathrm{SIWV}}$ depend on atmospheric humidity.

As shown in Fig. 5 (top), the SD of $\Delta_{\text {SIWV }}$ increases slightly with increasing WVR IWVs. For WVR IWVs above $25 \mathrm{~kg} \mathrm{~m}^{-2}$, the biases of $\Delta_{\text {SIWV }}$ drift slightly towards negative values, while rather positive values are observed below $10 \mathrm{~kg} \mathrm{~m}^{-2}$. The variations in $\Delta_{\mathrm{SIWV}}$ generally increase at higher WVR IWVs, and GPS SIWVs are increasingly smaller than WVR SIWVs. Regarding the bias tendency, a similar behavior can be seen for relative $\Delta_{\text {SIWV }}$ (Fig. 5, bot-
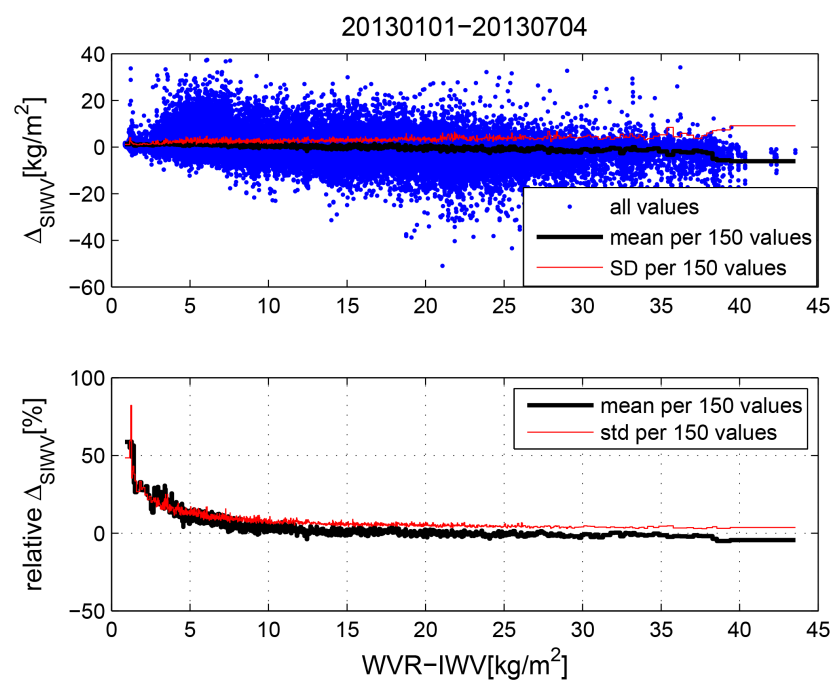

Figure 5. Relation between $\Delta_{\text {SIWV }}$ and WVR IWVs measured in zenith direction (top); relation between relative $\Delta_{\mathrm{SIWV}}$ and WVR IWVs measured in zenith direction (bottom). Blue points are all validation values. Black points are means of every 150 values along the axis, and the red line is their corresponding SD.

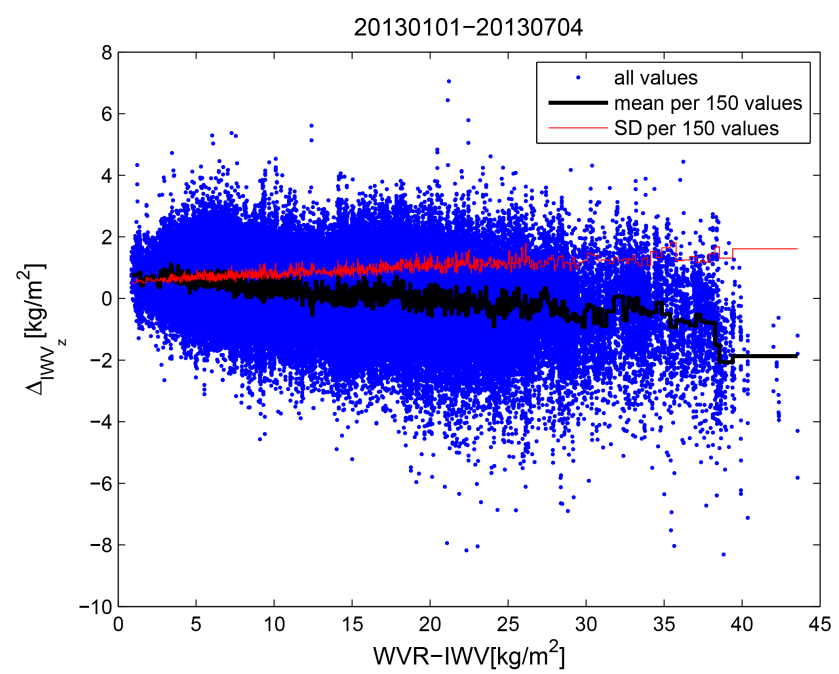

Figure 6. Relation between $\Delta_{\mathrm{IWV}_{z}}$ and WVR IWVs measured in zenith direction. Blue points are all validation values. Black points are means of every 150 values, and the red line is their corresponding SD.

tom), while the SD shows the opposite behavior to the absolute comparisons as it decreases with increasing WVR IWVs. Due to observation values near the expected measurement accuracy, relative bias and SD reach large values at very dry conditions (WVR IWV below $3 \mathrm{~kg} \mathrm{~m}^{-2}$ ). Instead of the relative $\Delta_{\mathrm{SIWV}}$, the relation between $\Delta_{\mathrm{IWV}}$ and WVR IWV is shown in Fig. 6. The same tendency is observed with the bias and SD of $\Delta_{\mathrm{IWV}_{z}}$. A linear tendency of the differences from positive values to negative values is observed in the figures. 

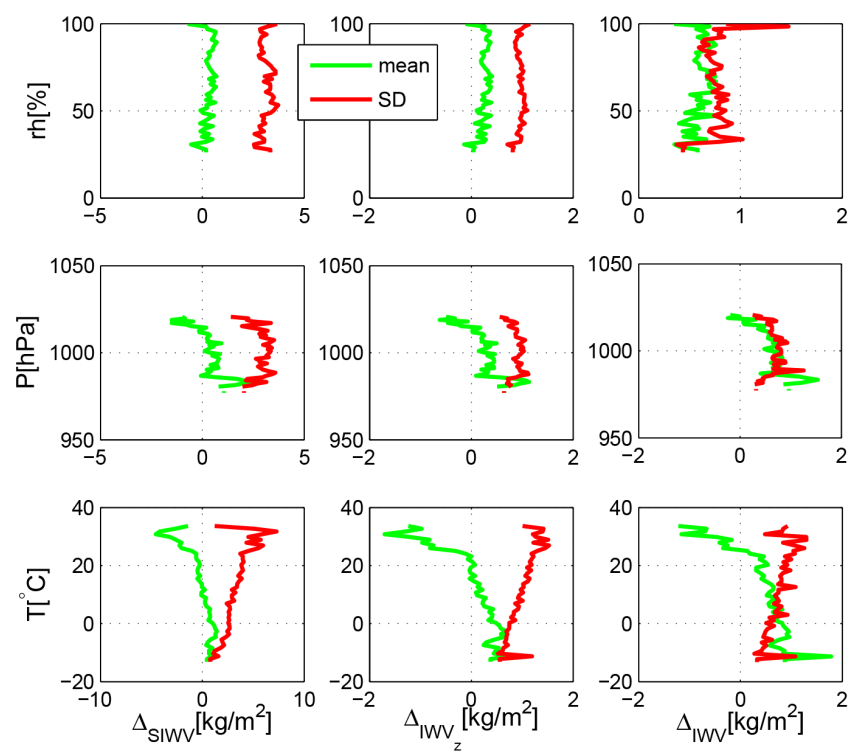

Figure 7. Relation between the mean (green) and SD (red) of

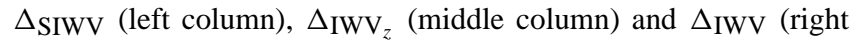
column) and relative humidity $(\mathrm{RH})$ (top row), pressure $(P)$ (middle row) and temperature ( $T$ ) (bottom row).

\subsection{Dependency of the bias on ground weather conditions}

Pressure $(P)$, temperature $(T)$ and relative humidity $(\mathrm{RH})$ were measured by the meteo sensor of the type Vaisala PTU200 near the POTS station with high accuracy. Pressure and temperature were used to calculate the GPS SIWV and have an effect on the estimated SIWV. Therefore, pressure and temperature may also influence the comparison results.

The comparisons between RH, $T, P$ and the differences are shown in Fig. 7. $\Delta_{\text {IWV }}$ is the difference between the WVR-measured IWV in zenith direction and the GPS-ZTDderived IWV. The GPS IWV has a temporal resolution of $15 \mathrm{~min}$. Due to the WVR measurements periodically switching between GPS satellite tracking and zenith IWV observation mode every 5 min, only about 14132 GPS IWVs have the corresponding WVR IWVs within the time interval of \pm 3 min. In Fig. 7 (middle), the biases of $\Delta_{\mathrm{SIWV}}, \Delta_{\mathrm{IWV}_{z}}$ and $\Delta_{\text {IWV }}$ change considerably with the variation in pressure. It is difficult to find the dependency between pressure and the differences because of the strong variability. Similarly to pressure, no clear relation between the relative humidity and differences is found (Fig. 7, top). In contrast, the biases of $\Delta_{\mathrm{SIWV}}, \Delta_{\mathrm{IWV}_{z}}$ and $\Delta_{\mathrm{IWV}}$ decrease with increasing temperature, and the corresponding SDs increase at the same time (Fig. 7, bottom). A similar tendency is observed between the differences and WVR IWVs (see Figs. 5, 6). The relation between the IWV and temperature is shown in Fig. 8. The amount of water vapor increases with temperature, showing the temperature effect on the atmospheric water-holding ca-

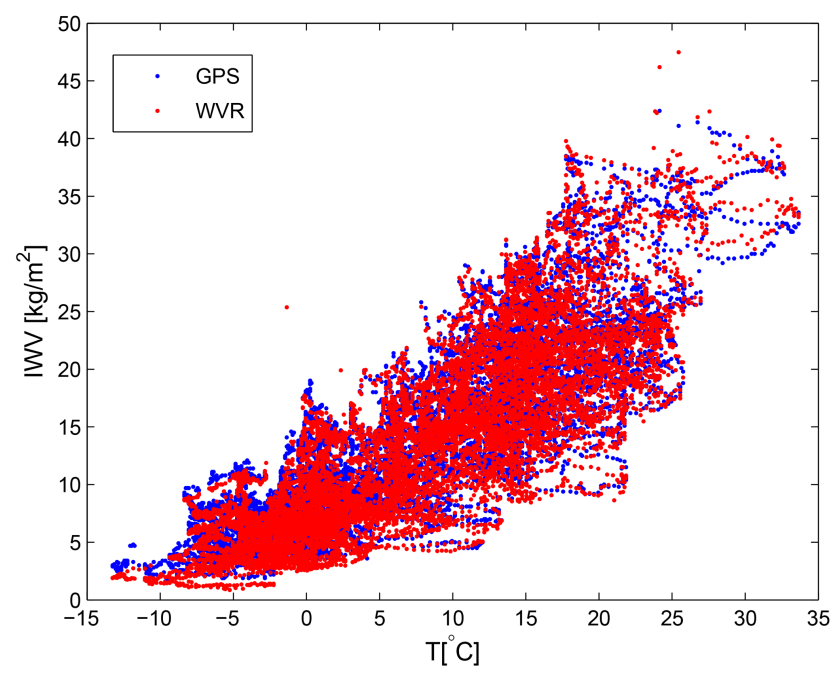

Figure 8. Relation between the measured IWV and temperature: scatterplots of GPS and WVR IWV observations.

pacity. In Fig. 8, the water vapor amount of GPS observations at high temperatures is smaller than the measured WVR IWVs.

\section{Conclusions}

The validation of the GPS slant delay data with WVR provides evidence of good agreement between the compared data. The bias between GPS and WVR data is $-0.40 \mathrm{~kg} \mathrm{~m}^{-2}$, with an rms of $3.15 \mathrm{~kg} \mathrm{~m}^{-2}$, which is dominated by the large differences at low elevation angles. With the cutoff elevation of $15^{\circ}$, the rms of difference in SIWV is only $1.80 \mathrm{~kg} \mathrm{~m}^{-2}$. The GPS SIWV has an accuracy comparable to that of the WVR data.

In this study the relations between $\Delta_{\mathrm{SIWV}}, \Delta_{\mathrm{IWV}_{z}}$ and five possible influential factors are tested. It indicates a relative dependency between $\Delta_{\text {SIWV }}$ and elevation angles. However, $\Delta_{\mathrm{IWV}_{z}}$ are almost as good at different elevation angles. It indicates that the relative error of GPS SIWV is almost constant at different elevation angles.

Both biases of $\Delta_{\text {SIWV }}$ and $\Delta_{\mathrm{IWV}_{z}}$ show a weak dependence on atmospheric humidity, changing from slightly positive values at low IWV conditions to slightly negative values at high IWV. Similar effects are observed with the relation to temperature, which can be explained by the temperature dependence of the atmospheric water-holding capacity. GPS estimates are smaller than WVR SIWVs in most cases at high temperature or when there are large water vapor amounts. The study shows that the ground weather condition has some influence on the difference in SIWV, especially the temperature or humidity condition.

These differences (negative biases at high temperatures or very humid conditions) can be caused by the errors in both GPS and WVR data. Further studies are planned with GPS 
data and WVR data in satellite tracking mode. Furthermore, the adjustments to GPS data processing parameters with the help of WVR data would be investigated, which may contribute to improvements of GPS product quality.

Acknowledgements. The authors thank the Helmholtz Centre Potsdam, German Research Centre for Geosciences (GFZ), for supporting this work.

The service charges for this open access publication have been covered by a Research Centre of the Helmholtz Association.

Topical Editor V. Kotroni thanks G. Guerova and one anonymous referee for their help in evaluating this paper.

\section{References}

Bender, M., Dick, G., Wickert, J., Schmidt, T., Song, S., Gendt, G., Ge, M., and Rothacher, M.: Validation of GPS slant delays using water vapour radiometers and weather models, Meteorol. Z., 17, 807-812, 2008.

Bender, M., Dick, G., Ge, M., Deng, Z., Wickert, J., Kahle, H.-G., Raabe, A., and Tetzlaff, G.: Development of a GNSS water vapour tomography system using algebraic reconstruction techniques, Adv. Space Res., 47, 1704-1720, doi:10.1016/j.asr.2010.05.034, 2011.

Bennitt, G. V. and Jupp, A.: Operational assimilation of GPS zenith total delay observations into the Met Office numerical weather prediction models, Mon. Weather Rev., 140, 2706-2719, 2012.

Bevis, M., Businger, S., Herring, T. A., Rocken, C., Anthes, R. A., and Ware, R. H.: GPS meteorology: Remote sensing of atmospheric water vapor using the Global Positioning System, J. Geophys. Res., 97, 15787-15801, doi:10.1029/92JD01517, 1992.

Bevis, M., Businger, S., Chiswell, S., Herring, T. A., Anthes, R. A., Rocken, C., and Ware, R. H.: GPS meteorology: Mapping zenith wet delays onto precipitable water, J. Appl. Meteorol., 33, 379-386, 10.1175/15200450(1994)033<0379:GMMZWD>2.0.CO;2, 1994.

Boehm, J., Werl, B., and Schuh, H.: Troposphere mapping functions for GPS and very long baseline interferometry from European Centre for Medium-Range Weather Forecasts operational analysis data, J. Geophys. Res.-Sol. Ea., 111, B02406, doi:10.1029/2005JB003629, 2006a.

Boehm, J., Niell, A., Tregoning, P., and Schuh, H.: Global Mapping Function (GMF): A new empirical mapping function based on numerical weather model data, Geophys. Res. Lett., 33, L07304, doi:10.1029/2005GL025546, 2006b.

Braun, J., Rocken, C., and Liljegren, J.: Comparisons of line-ofsight water vapor observations using the global positioning system and a pointing microwave radiometer, J. Atmos. Ocean. Tech., 20, 606-612, 2003.

Davis, J., Herring, T., Shapiro, I., Rogers, A., and Elgered, G.: Geodesy by radio interferometry: Effects of atmospheric modeling errors on estimates of baseline length, Radio Sci., 20, 15931607, doi:10.1029/RS020i006p01593, 1985.

Deng, Z., Bender, M., Zus, F., Ge, M., Dick, G., Ramatschi, M., Wickert, J., Löhnert, U., and Schön, S.: Validation of tropospheric slant path delays derived from single and dual frequency GPS receivers, Radio Sci., 46, RS6007, doi:10.1029/2011RS004687, 2011.

Emardson, T. R., Elgered, G., and Johansson, J. M.: Three months of continuous monitoring of atmospheric water vapor with a network of Global Positioning System receivers, J. Geophys. Res., 103, 1807-1820, doi:10.1029/97JD03015, 1998.

Gendt, G., Dick, G., and Soehne, W.: GFZ Analysis Center of IGS. Annual Report 1998, International GPS Service for Geodynamics, 79-87, 1998.

Gendt, G., Dick, G., Reigber, C., Tomassini, M., Liu, Y., and Ramatschi, M.: Near real time GPS water vapor monitoring for numerical weather prediction in Germany, J. Meteorol. Soc. Jpn., 82, 361-370, 2004.

Gendt, G., Ge, M., Nischan, T., Uhlemann, M., Beeskow, G., and Brandt, A.: GFZ Analysis Center of IGS, Annual Report for 2011, International GNSS Service, Technical Report 2011, Astronomical Institute, University of Bern, 2011.

Gutman, S. I., Sahm, S. R., Benjamin, S. G., Schwartz, B. E., Holub, K. L., Stewart, J. Q., and Smith, T. L.: Rapid retrieval and assimilation of ground based GPS precipitable water observations at the NOAA Forecast Systems Laboratory: Impact on weather forecasts, J. Meteorol. Soc. Jpn., 82, 351-360, 2004.

Kneifel, S., Crewell, S., Löhnert, U., and Schween, J.: Investigating water vapor variability by ground-based microwave radiometry: Evaluation using airborne observations, IEEE T. Geosci. Remote, 6, 157-161, doi:10.1109/LGRS.2008.2007659, 2009.

Ning, T., Elgered, G., and Johansson, J.: The impact of microwave absorber and radome geometries on GNSS measurements of station coordinates and atmospheric water vapour, Adv. Space Res., 47, 186-196, 2011.

Rose, T., Crewell, S., Löhnert, U., and Simmer, C.: A network suitable microwave radiometer for operational monitoring of the cloudy atmosphere, Atmos. Res., 75, 183-200, doi:10.1016/j.atmosres.2004.12.005, 2005.

Shangguan, M.: Analysis and derivation of the spatial and temporal distribution of water vapor from GNSS observations, Ph.D. thesis, TU Berlin, 2014.

Shangguan, M., Bender, M., Ramatschi, M., Dick, G., Wickert, J., Raabe, A., and Galas, R.: GPS tomography: validation of reconstructed 3-D humidity fields with radiosonde profiles, Ann. Geophys., 31, 1491-1505, doi:10.5194/angeo-31-1491-2013, 2013.

Shoji, Y.: A study of near real-time water vapor analysis using a nationwide dense GPS network of Japan, J. Meteorol. Soc. Jpn., $87,1-18,2009$.

Smith, T. L., Benjamin, S. G., Gutman, S. I., and Sahm, S.: Shortrange forecast impact from assimilation of GPS-IPW observations into the Rapid Update Cycle, Mon. Weather Rev., 135, 2914-2930, 2007.

Ware, R., Alber, C., Rocken, C., and Solheim, F.: Sensing integrated water vapor along GPS ray paths, Geophys. Res. Lett., 24, 417420, doi:10.1029/97GL00080, 1997.

Wolfe, D. E. and Gutman, S. I.: Developing an operational, surfacebased, GPS, water vapor observing system for NOAA: Network design and results, J. Atmos. Ocean. Tech., 17, 426-440, 2000.

Zumberge, J., Heflin, M., Jefferson, D., Watkins, M., and Webb, F.: Precise point positioning for the efficient and robust analysis of GPS data from large networks, J. Geophys. Res., 102, 50055017, doi:10.1029/96JB03860, 1997. 